B.J. Kraynack MD, N.W. Lawson MD, J. Gintautas MD PHD

\title{
Neuromuscular blocking action of verapamil in cats
}

The effects of the calcium (slow) channel blocker verapamil, on non-cardiac excitable membranes were examined in vivo. In barbiturate anaesthetized cats, the effect of intravenously administered verapamil $(0.1,0.2$, and $0.4 \mathrm{mg} \cdot \mathrm{kg}^{-1}$ ) on isometric twitch amplitude of the flexor carpi radialis muscie, elicited by indirect and direct electrical stimulation, was determined. At all doses tested, verapamil significantly reduced muscle twitch amplitude from control values. The effect of dosage on twitch reduction was far more pronounced for indirect than direct stimulation. Full recovery to control was observed by 90 minutes only with the lowest dose $\left(0.1 \mathrm{mg} \cdot \mathrm{kg}^{-1} \mathrm{~N}\right)$. Reduction of iwitch amplitude (direct and indirect) lasted the duration of the experiment ( 180 minutes) for the two higher doses of verapamil. No significant changes in blood pressure, cardiac rate or rhyth were observed. The specific size and mechanism of verapamil's neuromuscular blocking action remains unclear. In clinical situations where potent inhaiation agents, adjuncts or neuromuscular blocking agents may be used, therapeutic doses of verapamil may interact to promote muscle weakness.

Key words

IONS: calcium; MEMBRANEs: muscle, nerve synapse; NEUROMUSCULAR TRANSMISSION: verapamil, neuromuscular junction, neuromuscular blocker; PHARMACOLOGY: verapamil.

From the Anesthesiology Research Laboratories, Texas Tech University Health Science Center, School of Medicine, Lubbock, Texas.

Supported in part by a Biomedical Research Support Grant from the Texas Tech University Health Sciences Center.

Address correspondence to: Dr. B.J. Kraynack, Richland Memorial Hospital, 3301 Harden Street; Columbia, S.C. 29203, USA.
The pharmacologic properties of the calcium (slow) channel blocking agent, verapamil, has made it useful in the treatment of recurrent supraventricular arrhythmias in man. ${ }^{1-3}$ Verapamil, a phenylacetonitrile, inhibits the ionic current carried through the slow channel by calcium and/or sodium ions. ${ }^{3.4}$ Despite the wide spectrum of biological functions dependent on calcium ions, the pharmacologic effects of verapamil and other calcium (slow) channel blockers appears restricted to the cardiovascular system. ${ }^{3,5}$

In a qualitative study in cats, the intra-arterial administration of verapamil $(100-400 \mu \mathrm{g})$ reduced direct and indirectly elicited muscle twitch amplitude. ${ }^{6}$ In dogs, we correlated prolongation of the $P R$ interval of the EKG with maximum depression of muscle twitch height following intravenous administration of verapamil. ${ }^{7}$ Clinjcally significant neuromuscular blocking action of verapamil has not been reported to date. In view of the fact that increasing numbers of patients in the perioperative period will be treated with verapamil ${ }^{8}{ }^{8}$ knowledge of its effects on noncardiovascular tissues may be of clinical importance. The following study was designed to investigate in cats the effects of intravenously administered verapamil, in the therapeutic dose range recommended for man, on isometric muscle twitch amplitude.

\section{Methods}

Seventeen adult mongrel cats of either sex weighing 2-3 kg were anaesthetized with sodium pentobarbital ( $30 \mathrm{mg} \cdot \mathrm{kg}^{-1}$ IV). Supplemental doses were given as needed. The animals were intubated without muscle relaxant and mechanically ventilated $\left(\mathrm{FIO}_{2}=1.0\right)$ to maintain $\mathrm{PaCO}_{2}$ at 40 torr. A circulating water blanket was used to maintain rectal temperature between $37-39^{\circ} \mathrm{C}$. The electrocardiogram (Lead II) continuously recorded cardiac rate and rhythm.

Cannulas were placed in a femoral artery for 
TABLE 1 Effect of verapamil on indirect and direct muscle twitch amplitude. Mean \pm SEM (percent of control).

\begin{tabular}{|c|c|c|c|c|c|c|}
\hline \multirow[b]{2}{*}{ Dose $\left(\mathrm{mg} \cdot \mathrm{kg}^{-I}\right)$} & \multicolumn{6}{|c|}{ Time (minutes) } \\
\hline & 0 & 15 & 30 & 60 & 90 & 180 \\
\hline \multicolumn{7}{|c|}{ Indirect Stimulation } \\
\hline 0.1 & 100 & $75.0 \pm 1.7^{*}$ & $80.3 \pm 3.7$ & $94.7 \pm 2.7$ & 100 & - \\
\hline 0.2 & 100 & $81.5 \pm 6.4$ & $80.0 \pm 4.7$ & $68.0 \pm 6.4^{*}$ & $56.3 \pm 15.6^{*}$ & $37.0 \pm 37.0^{*}$ \\
\hline 0.4 & 100 & $87.4 \pm 4.0$ & $73.3 \pm 11.5^{*}$ & $64.0 \pm 8.7^{*}$ & $34.3 \pm 11^{*}$ & $17.0 \pm 11^{*}$ \\
\hline \multicolumn{7}{|l|}{ Direct Stimulation } \\
\hline 0.1 & 100 & $75.3 \pm 3.2^{*}$ & $75.7 \pm 10.2^{*}$ & $86.7 \pm 5.8$ & $93.3 \pm 6.7$ & - \\
\hline 0.2 & 100 & $81.8 \pm 3.1$ & $78.3 \pm 3.3^{*}$ & $79.5 \pm 7.2^{*}$ & $81.0=9.0$ & $67.0 \pm 3.0^{*}$ \\
\hline 0.4 & 100 & $79.1=9.9$ & $74.4 \pm 8.1^{*}$ & $63.9 \pm 13.2^{*}$ & $69.6 \pm 8.1^{*}$ & $61.8 \pm 4.1^{*}$ \\
\hline
\end{tabular}

Pairwise differences between levels of dose, tested for significance by means of Tukey's HSD test.

Criticel difference set at $\alpha=0.05 ; 24.9$ for indirect and 20.4 for direct.

* = significant at 0.05 level.

intra-arterial pressure monitoring and arterial blood sampling and in a femoral vein for intravenous fluid and drug administration. The blood pressure was continuously monitored. Each animal received approximately $10 \mathrm{ml} \cdot \mathrm{kg}^{-1} \cdot \mathrm{h}^{-1}$ of 0.9 per cent saline with 5 per cent glucose.

The right forelimb of each cat was used. The flexor carpi radialis muscle and its nerve were surgically exposed. Platinum wire electrodes were placed on the nerve for indirect electrical stimula tion. Another set of electrodes was placed in the muscle belly for direct electrical stimulation. The muscle was attached by suture to a Grass FT03C force-displacement transducer. Isometric muscle twitch amplitude to direct and indirect stimulation was alternately recorded on a Hewlett-Packard 7758-B polygraph recorder. Stimulation was induced supramaximally with a Grass $\$ 48$ stimulator at a rate of one per second. The duration of the square wave stimuli was $0.2 \mathrm{msec}$ for nerve and 2.0 msec for muscle. Viability of the preparation was tested in another group of cats $(\mathrm{N}=3)$, which received saline injection.

Three doses of verapamil* were examined: 0.1 $(\mathrm{N}=3$ cats $), 0.2(\mathrm{~N}=4)$ and $0.4(\mathrm{~N}=7) \mathrm{mg} \cdot \mathrm{kg}^{-1}$ and were injected intravenously over a three-minute period with a constant infusion pump. The EKG and twitch height were recorded every five minutes up to 30 minutes after drug injections; then every 15 minutes up to three hours. The experiment was terminated at three hours.

"Isoptin, Knoll Pharmaceuticals, Whippany, New Jersey.
Data are expressed as the mean $\pm S E M$, and reported as percent of control value (zero time). Data were subjected to split plot factorial analysis of variance. ${ }^{9}$ Tukey's HSD test was used to test pairwise differences of verapamil induced changes at comparable times over the course of the experiment. Critical difference was set at $\alpha=0.05$. Significant difference between values was assumed when $\mathrm{p}<0.05$. A variable was considered to have returned to control level when the $p$ value compared to control was greater than 0.05 .

\section{Results}

In the saline-treated control group of cats, we observed no change in twitch amplitude or cardiac parameters (rate, rhythm, blood pressure) over the time course of the experiment. Verapamil, at each dose tested, significantly reduced isometric muscle twitch amplitude elicited by direct and indirect stimulation in cats after intravenous administration (Table I). The reduction of muscle twitch height following indirect and direct stimulation are graphically presented in Figures $1 \mathrm{~A}$ and $1 \mathrm{~B}$ respectively. Time of onset of twitch reduction varied according to dose. A wide range of inter-animal response was observed.

Indirectly and directly elicited twitch were significantly reduced at 15 minutes by $0.1 \mathrm{mg} \cdot \mathrm{kg}^{-1}$ verapamil. Full recovery to control value occurred within 30-60 minutes and was observed only with this dose. Significant reductions of amplitude from control did not occur until 30 to 60 minutes, depending on stimulation mode, for the two higher doses of verapamil. Twitch height stabilized, at 


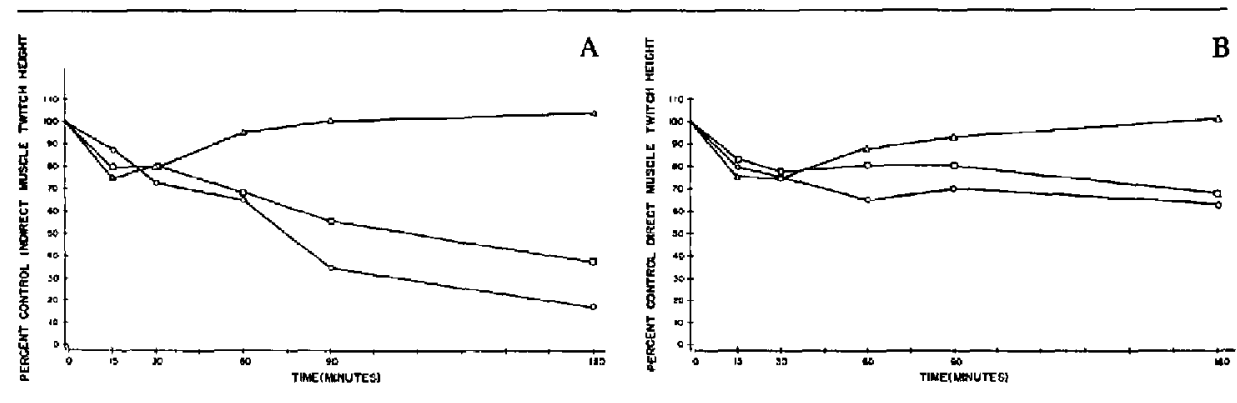

FGURE 1A and IB Mean reductions in indirect and direct twitch height by intravenous verapamil in cats. Triangles, squares and circles represent responses to $0.1,0.2$ and $0.4 \mathrm{mg} \cdot \mathrm{kg}^{-1}$, respectively. See Table I for statistical analysis, and SEM.

greatly reduced levels, between 90 and 180 minutes for the two higher doses regardless of the stimulation mode. Reduction of amplitude lasted the duration of the experiment (180 minutes) for the two higher doses of verapamil. Although most of the reductions (indirect and direct) induced by the two higher doses of verapamil were each statistically different from control between 30 and 180 minutes, there was no significant difference between them $(\mathrm{p}>0.05)$ at these times. A P value $>$ 0.05 may represent a lack of statistical significance but not necessarily functional significance.

No change in heart rate, rhythm or PR interval was observed. Statistically insignificant and transient (1-2 minute) decreases in mean arterial pressure were observed following all three doses of verapamil. Recovery to preinjection values occurred by five minutes in all groups.

\section{Discussion}

The results clearly demonstrate that verapamil, over the therapeutic dose range employed in man, significantly reduces muscle twitch amplitude in intact cats following direct and indirect electrical stimulation. Further, the recovery of twitch amplitude at higher doses was not observed in this study. The results confirm and extend our previously reported qualitative findings that verapamil produced neuromuscular blockade after intra-arterial injection in cats without altering the cardiac rate, rhythm or conduction. ${ }^{6}$ In dags, however, intravenous verapamil produced a significant but recoverable reduction in muscle twitch height to indirect stimulation, the beginning of which was correlated to the onset of a PR interval increase. ${ }^{7}$ Maximum reduction of twitch height corresponded to the maximum PR interval widening or onset of conduction arrhythmias. The differences in neuromuscular and in vardiac effects may be related to differences in species studied.

Indirect twitch height was reduced more than direct twitch suggesting that verapamil may act directly on the nerve. Inhibition of calcium flux by verapamil in low concentrations $\left(10^{-6}-10^{-8} \mathrm{M}\right)$ has been convincingly demonstrated for cardiac and smooth vascular muscle. ${ }^{10-13}$ Neurons are more resistant to the effects of calcium (slow) channel blockers. D-600 verapamil (the methoxy derivative) substantially reduces the slow inward calcium current (slow channel) in squid axon without altering the potassium current. ${ }^{14}$ Singh and VaughnWilliams ${ }^{15}$ found verapamil 1.6 times more effective than procaine as a local anaesthetic. We reported that DL-verapamil possessed dose-related and frequency-dependent fast channel (local anesthetic) blocking activity in isolated rat sciatic nerves equivalent on a molar basis $(5 \mathrm{mM})$ to procaine. ${ }^{16}$ Although the concentrations of verapamil which perfused the nerve in vivo were not known, a local anaesthetic action by verapamil in the fine terminals of the motor nerve may explain the observed reductions in indirect twitch height. Van der Kloot and $\mathrm{Kita}^{17}$ observed in crayfish muscle that increasing doses of verapamil increased the motor nerve stimulation threshold while decreasing the amplitude of cxcitatory junctional potentials. These findings are consistent with the known fast channel (local anaesthetic) blocking action of verapamil.

Verapamil may exert its effect directly at the synaptic level of the neuromuscular junction. Publicover and Duncan ${ }^{18}$ observed in vitro that verap. 
amil $\left(10^{-4} \mathrm{M}\right)$ abolished indirectly elicited muscle twitch in frog nerve-muscle preparations. Similarly, in rat phrenic nerve-diaphragm preparations, verapamil $(0.06 \mathrm{mM})$ inhibited indirect muscle twitch. ${ }^{19}$ In our laboratories, verapamil ( $5 \mathrm{mM}$ ) and pancuronium $(0.07 \mathrm{mM})$ equally reduced indirect twitch amplitude in isolated bullfrog sciatic nervesartorius muscle preparations. However, a combination of these drugs significantly potentiated the reduction of twitch height to indirect stimulation. ${ }^{20}$ The neuromuscular blocking action could result from a presynaptic action of verapamil. Verapamil may reduce calcium conductance of the presynaptic membrane, alter intracellular presynaptic calcium pools, cyclic AMP levels, or inhibit the membrane calcium pump. These actions may interfere with the mobilization of acetylcholine or its actual release.

Alternatively, a post-junctional site of action could also be responsible. Verapamil $\left(10^{-4}\right.$ $10^{-6} \mathrm{M}$ ) blocks acetylcholine-induced toad skeletal muscle contraction in vitro in a non-competitive manuer. ${ }^{21}$ In this report, d-tubocurare $\left(10^{-5} \mathrm{M}\right)$, but not procaine $\left(10^{-3} \mathrm{M}\right)$, inhibited the action of acetylcholine. Thus, it appears that verapamil, like curare, may also alter muscle end plate sensitivity to acetylcholine as well as inhibiting transmitter release. The authors also observed that calcium significantly enhanced the inhibiting action of verapamil.

Little direct evidence is available which supports the hypothetical pre or post-synaptic actions of verapamil. The amplitude of miniature end-plate potentials (MEPP) is changed by the sensitivity of the postsynaptic receptor (i.e., d-tubocurare); whereas the frequency of MEPP is influenced by agents (high potassium) affecting the presynaptic site. 22 For example, Nachshen and Blaustein ${ }^{23}$ repoited that verapamil and D-600 verapamil did not reduce or block potassium-stimulated transmitter release (i.e., increased MEPP frequency) in the frog neuromuscular junction; whereas, manganese by blocking calcium (slow) channels did. Others ${ }^{18}$ have reported dose related differential presynaptic effects on neurotransmitter release with no observed post-junctional effects. ${ }^{17.18}$ The inference that verapamil acts on synaptic membranes must await more definitive lines of evidence.

The interaction of time and dose in this study is interesting. Two separate pharmacodynamic phenomena are apparent. First, the reversible and rapid depression of twitch height was observed only with the lowest dose $\left(0.1 \mathrm{mg} \cdot \mathrm{kg}^{-1}\right)$ of verapamil. This immediate effect may be directly related to orset of the peak tissue levels of verapamil. High lipid affinity of verapamil and its reported distribution values $^{24}$ suggest that the drug would be distributed preferentially in membrane structures. ${ }^{25}$ Bondi $^{25}$ observed that reversal of twitch depression by washing was slow in vitro, and impossible if washout was not started immediately. We observed similar effects in our in vitro studies on nerves ${ }^{16}$ and nerve-muscle preparations. ${ }^{20}$ Keefe and Kates ${ }^{26}$ have reported that verapamil accumulates to levels in the myocardium which are six-fold greater than the plasma concentration and this ratio remains constant with time. Verapamil rapidly accumulates in high concentrations in tissues and these levels are maintained for significant periods

The second phenomenon is characterized by irreversible depression of slow onset. The two higher doses of verapamil had no significant effects until 30 to 60 minutes after administration, after which no recovery was observed. The maximum reduction of twitch height did not occur until 90 to 180 minutes after injection. Reduction of neuromuscular transmission is observed at a time when serum levels should be decreasing.

Recent reports have demonstrated significant delay in comelation between peak verapamil effect and plasma concentration. Hysteresis analysis following intravenous administration shows that $P R$ interval prolongation correlates with plasma verapamil concentrations only after a 15-30-minute lag period. ${ }^{27}$ Kapur and Flacke also reported differences in effects of verapamil which could not be explained by the reported pharmacokinetics of the drug. Antiarrhythmic effects were observed in dogs after previously depressed haemodynamic functions had returned to normal and verapamil levels could be expected to be low. The evidence suggests that deficiencies exist in our understanding of the pharmacodynamics and kinetics of verapamil. Finally, active metabolites like norverapamil or others may accumulate to high levels over a prolonged period of time and may contribute significant pharmacologic activity. ${ }^{23.29}$ These mechanisms, either singly or in combination, may be responsible for the immediate and delayed block observed in cats.

We have demonstrated significant neuromuscular blocking action of verapamil in cats. The evidence suggests that the effects of verapamil on 
excitable membranes and synapses may be quite complex. Verapamil possesses other pharmacologic properties not related to calcium (slow) channel blockers and may alter noncardiovascular membranes. Verapamil is neither a selective nor specific calcium (slow) channel blocker. The dual inhibition of fast and slow channel activity, as well as interference with neuromuscular transmission may account for these findings. Clinically significant neuromuscular blocking action by verapamil has not been reported to date. Based on the fact that many drugs used during the administration of an anaesthetic may induce muscle weakness, these findings may have direct clinical application. Potential interactions with verapamil by potent inhalation agents, antibiotics, neuromuscular blockers and other drugs that possess neuromuscular blocking action must be anticipated. Until appropriate clinical studies confirm or deny these possibilities, we suggest that anaesthesiologists anticipate and exert caution in such situations.

\section{Acknowledgements}

The authors thank Knoll Pharmaceuticals, Whippany, New Jersey, for supplying verapamil, David Coons for statistical analysis, and Barbara McAnulty and Susan Sawyer for assistance with preparation of the manuscript.

\section{References}

1 Antman EM, Stone PH, Muller JE, Braunwald E. Calcium channel blocking agents in the treatment of cardiovascular disorders. Part $\mathrm{l}$ : basic and clinical electrophysiologic effects. Ann Int Med 1980; 93: 875-85.

2 Mangiardi LM, Hariman RJ, MCAllister RG $J r$, Bhargava V, Surawicz B, Shabeti R. Electrophysiologic and hemodynamic effects of verapamil: correlation with plasma concentrations. Circulation 1978; 57: 366-72.

3 Zsoter TT. Calcium antagonists. Am Heart J 1980; 99: 805-10.

4 Henry $P D$. Comparative pharmacology of calcium antagonists: nifedipine, verapamil and diltiazem. Am J Cardiol 1980; 46: 1047-58.

5 Singh BN, Ellrodt $G$, Peter GT. Verapamil: a review of its pharmacological properties and therapeutic use. Drugs 1978; 15: 169-97.

6 Kraynack BJ, Lawson NW, Gintautas $J$. Effects of verapamil on excitable membranes. Proc West Pharmacol Soc 1982; 25: 61-4.
7 Lawson NW, Kraynack BJ, Gintautas J. Neuromuscular and Electrocardiographic Responses to verapamil in dogs. Anesth Analg 1983; 62: 50-4.

8 Merin RG. Slow channel inhibilors, anesthetics, and cardiovascular function. Anesthesiology 1981; 55: 198-200.

9 Kirk RE. Experimental Design: Procedures for the Behavioral Sciences. Belmont, California: Brooks/ Cole Pub Co, 1968.

10 Fleckenstein A. Specific pharmacology of calcium in myocardium, cardiac pacemakers, and vascular smooth muscle. Ann Rev Pharmacol Toxicol 1977; 17: $149-66$.

11 Rosenberger $L$, Triggle DJ. Calcium, Calcium Translocation and Specific Calcium Antagonists. In: Weiss, G.B., ed. Calcium in Drug Action. New York: Plenum, 1978.

12 Hagiwara S, Byerly L. Calcium channel. Ann Rev Neurosci 1981; 4: 69-125.

13 Nayler WG, Ponle-Wilson Ph. Calcium antagonists: definition and mode of action. Basic Res Cardiol 1981; 76: 1-15.

14 Baker $P F$, Meves $H$, Ridgway EB. Effects of manganese and other agents on the calcium uptake that follows depolarization of squid axons. J. Physiol (Lond) 1973; 231: 511-26.

15 Singh BN, Vaughn-Williams EM. A fourth class of anti-dysrhythmic action? effect of verapamil on oubain toxicity, on atrial and ventricular intracellular potentials, and on other features of cardiac function. Cardiovasc Res 1972; 6: 109-19.

16 Kraynack BJ, Lawson NW, Gintautas $J$. Local anesthetic effect of verapamil in vitro. Regional Anesth 1982; 7: 114-7.

17 Van der Kloot W, Kita H. The effects of the "calcium-antagonist" vcrapamil on muscle action potentials in the frog and crayfish and on neuromuscular transmission in the crayfish. Comp Biochem Physiol 1975; 50C: 121-5.

18 Publicover SJ, Duncan CJ. The action of verapamil on the rate of spotaneous release of transmitter at the frog neuromuscular junction. Eur J Pharmacol 1979; 54: 119-27.

19 Ribeiro JA. Dominquez ML. Goncalves MJ. Purine effects at the neuromuscular junction and their modification by theophylline, imidazole and verapamil. Arch Int Pharmacodyn 1979; 238: 206-19.

20 Kraynack BJ, Lawson NW, Gintautas $J$. Verapamil Reduces Indirect Muscle Twitch Amplitude and Potentiates Pancuronium in vitro. Anesthesiology 1982; 57: A265. 
21 Chiarandini $D J$, Bentley $P J$. The effects of verapamil on metabolism and contractility of the toad skeletal muscle. J. Pharmacol Exp Ther 1973; 186: 52-9.

$22 S u P C, S u W L$, Rosen $A D$. Pre- and postsynaptic effects of pancuronium at the neuromuscular junction of the mouse. Anesthesiology 1979; 50: 199 204.

23 Nachshen DA, Blaustein MP. The effects of some organic "calcium antagonists" on calcium influx in presynaptic nerve terminals. Mol Pharmacol 1979; 16: $579-86$

24 Bianchi $C P$, Bolton TC. Action of local anesthetics on coupling systems in muscle. J Pharmacol Exp Ther 1967; 157: 388-405.

25 Bondi $A Y$. Effects of verapamil on excitationcontraction coupling in frog sartorius muscle. $J$ Pharmacol Exp Ther 1978; 205: 49-57.

26 Keefe DL, Kates RE. Myocardial Disposition and Cardiac Pharmacodynamics of Verapamil in the Dog. J Pharmacol Exp Ther 1982; 220: 91-6.

27 McAllister RG Jr, Kirsten EB. The Phamacology of verapamil. IV. Kinetic and dynamic effects after single intravenous and oral doses. Clin Pharmacol Ther 1982; 31: 418-26.

28 Schomerus $M$, Spiegelholder B, Stieren B, Eichelbaum $M$. Physiological disposition of yerapamil in man. Cardiovascular Rescarch 1976; 10: 605-12.

29 Eichelbaum M. Ende M, Remberg G. Schomerus $M$ Dengler HJ. The Metabolism of DL- $\left[{ }^{14} \mathrm{C}\right]$ Verapamil in Man. Drug Metabolism and Disposition 1979; 7: 145-8.

\section{Résumé}

On a observé les effets du vérapamil, un agent bloquant de calcium (voie lente) sur des membranes non cardiaques in vivo. Chez des chats anesthésiés avec du barbiturate, on a vérifié les effets du vérapamil administré par voie intraveineuse $\left(0.1,0.2\right.$ et $0.4 \mathrm{mg} \cdot \mathrm{kg}^{-1}$ ) sur la phase isométrique de la contraction du muscle grand palmaire provoqué par stimulation électrique directe et indirecte. A toutes les doses vérifiées, le vérapamil réduisit significativement l'amplitude des contractions musculaires par rapport aux valeurs de conirbile. L'effet du dosage sur la réduction de contractions était beaucoup plus prononcé avec la stimulation indirecte que directe. La récupération au niveau du controle a été observée après 90 minutes seulement avec la dose la plus basse $\left(0.1 \mathrm{mg}^{\prime} \mathrm{kg}^{-1} \mathrm{I}\right.$.V.). La réduction de contractions (directe ou indirecte) dura tout le temps de l'expérience (180 minutes) pour les deux doses plus élevées de vérapamil. On n'observa pas de changements significatifs de pression artérielle, de rhythme ni de débit cardiaque. L'endroit spécifique et le mécanisme d'acrion du vérapamil comme agent bloquant neuromusculaire ne sont pas éclaircis. En situation clinique où des agents actifs d'inhalation, des traitements d'appoint et des agents bloquants neuromusculaires sont administrés, des doses thérapeutiques de verapamil peuvent interagir afin d'activer la faiblesse des muscles. 